\title{
Linguagem, Gênero, Sexualidade: Clássicos Traduzidos
}

ANA CRISTINA OSTERMANN \& BEATRIZ FONTANA (Org.)

SÃO PAULO: PARÁBOLA, 2010, 166 p.

Trata-se de uma coletânea de estudos clássicos sobre gênero e interação social. São artigos originalmente publicados em inglês sobre temática ainda pouco investigada no Brasil.

A organização dos capítulos mostra ao leitor como a produção de gênero e sexualidade foi reconhecida e examinada pelos estudos sociolinguísticos e apresenta isso de forma dialógica, o que permite reconstruir os avanços teóricos sobre o tema. A experiência das organizadoras da coletânea, e também das tradutoras, com gênero e interação social resultou em uma obra de excelente qualidade, revelando a autoridade para tratar do tema.

Para a área da Educação no Brasil, trata-se de uma obra ímpar porque, primeiramente, dispõe para leitoras e leitores artigos seminais sobre gênero e interação social, em língua portuguesa, ampliando o leque de acesso a essa literatura e contribuindo para a democratização do saber. Segundo, leva a refletir sobre a identidade de gênero, que nos constitui e nos oprime muitas vezes por meio de bullyings, mas que, por não identificarmos as marcas ou ações dessa opressão, não reagimos ou não levamos os nossos alunos a reagir diante de tal ação. E, terceiro, cada capítulo é uma oportunidade de reflexão sobre o tema e, também, parecer ser necessário para a existência do outro. O diálogo entre os autores dos artigos reflete, por vezes, o tom um pouco agressivo entre os pesquisadores e as suas filiações teórico-metodológicas. Isso é próprio da produção científica.

No primeiro capítulo, as organizadoras apresentam um panorama dos artigos que compõem a coletânea, justificando o percurso histórico dos estudos. A obra "Language and woman's place", de Robin Lakkoff, inaugura os estudos sobre linguagem e gênero, em 1975. Na sequência, a coletânea apresenta os artigos de Fishman, de 1978, West e Zimmerman, de 1987, e Tannen, de 1990, que investigaram diferenças entre as formas de falar de homens e mulheres e discutem o pressuposto de que diferenças de fato existam, analisando "déficit”, "dominância” e "diferença” na fala de homens e mulheres quando interagem. O sexto capítulo da coletânea é a tradução de um artigo de Eckert e McConnell-Ginet, de 1992, que representa o trabalho mais influente na mudança de atenção nas pesquisas em linguagem e gênero. Gênero é reconhecido como algo ocasionado nas interações, por isso precisa ser investigado a partir de falas situadas que evidenciem como ele é mutável e aprendido em comunidades de prática. O sétimo e oitavo capítulos têm dois artigos, respectivamente de Anna Lívia e Kira Hall, de 1997, e de Deborah Cameron, de 1998, que trabalham com a questão da performatividade. 
Lakoff, no segundo capítulo, "Linguagem e lugar da mulher", argumenta que é característica das mulheres privilegiarem a cooperação, a afiliação e a deferência entre os participantes de uma interação, em oposição ao estilo competitivo dos homens, o que resulta no desempoderamento das mulheres em interações com homens. Seus argumentos se apoiam em dados de introspeç̧ão, ou seja, dados da própria fala e da de conhecidos, recuperados e analisados com base em suas intuições. Por meio desses dados, a pesquisadora afirma que as mulheres experimentam discriminação, não apenas no modo pelo qual são ensinadas a usar a linguagem, como também no modo pelo qual o uso geral da linguagem as trata.

A autora aponta a presença de sexismo na linguagem. Há escolhas lexicais, como nomes de cores, bem como uso de perguntas de confirmação, padrões entonacionais, comportamentos, como docilidade e resignação, que são esperados das meninas; portanto, o comportamento que uma mulher aprende como sendo o "correto" impede que ela seja levada a sério como indivíduo. As palavras restritas à linguagem das mulheres sugerem que os conceitos aos quais se aplicam não são relevantes ao mundo real da influência e poder (masculinos). Lakoff conclui enfatizando que mudanças sociais geram mudanças linguísticas, e não o contrário. Para ela, no máximo, mudanças linguísticas podem influenciar, embora lenta e indiretamente, mudanças de atitude. Além disso, a pesquisadora destaca que o aprendizado de línguas deve ir além da sintaxe, fonologia e semântica. O contexto social é extremamente relevante para o desenvolvimento fluente de uma língua.

No terceiro capítulo, "O trabalho que as mulheres realizam nas interações”, Fishman examina a relação hierárquica entre homens e mulheres na interação diária. Para ela, poder pode ser analisado microssociologicamente, ou seja, poder e relações hierárquicas não são forças abstratas que operam sobre as pessoas, mas uma realização humana situada na interação diária. Os dados analisados pela pesquisadora foram transcritos de gravações em áudio de conversas diárias entre três casais heterossexuais.

A observação do desenvolvimento da conversa no processo interacional revelou um trabalho diferenciado realizado pelos sexos. Os homens realizam um trabalho em que predomina o controle das interações; entre as mulheres, prevalece o apoio. Elas precisam fazer mais perguntas, preencher os silêncios com palavras e usar mais iniciadores para ganhar a atenção de seus pares masculinos, o que ocorre, de acordo com Fishman, porque elas têm menos certeza de sucesso. “As mulheres são as trabalhadoras do 'serviço sujo’ da interação rotineira, e os 'produtos' gerados não são apenas as interações, mas, por meio delas, as realidades” (p. 45).

No quarto capítulo, "Pequenos insultos: estudo sobre interrupções em conversas entre pessoas desconhecidas e de diferentes sexos”, de 1983, 
West e Zimmerman formulam a hipótese de que o exercício de poder nas interações de homens e mulheres é mais eficaz quando silenciado, ou ainda quando tratado de forma indireta. Partindo de conclusões de uma pesquisa anterior, realizada em 1975, com falantes que se conheciam e possuíam certo grau de familiaridade entre si, os pesquisadores decidiram retomar a questão, desta vez analisando interações entre pessoas de diferentes sexos que não se conheciam previamente e que se encontraram em um ambiente não naturalístico. Apesar de condições marcadamente diferentes, foram observados essencialmente os mesmos padrões - as mulheres, e não os homens, interrompem mais para conseguir dizer alguma coisa -, fato que levou os pesquisadores a afirmarem que os padrões observados são uma característica básica das interações entre homens e mulheres. Como resultados, West e Zimmerman entenderam haver uma recusa por parte dos homens a permitir às mulheres uma posição igualitária, como parceiras conversacionais. Para eles, "a assimetria na iniciação da interrupção é, em outras palavras, um meio de 'fazer' poder em interações face a face, na medida em que poder está implicado no que significa ser um homem em relação a uma mulher, e também é um meio de ‘fazer' 'gênero'” (p. 65).

Os pesquisadores destacam que, diferentemente do que afirmam, em 1974, Sacks, Schegloff e Jefferson, sobreposições não seriam todas as instâncias de simultaneidade e que essas práticas não poderiam ser explicadas somente pela operação do sistema de tomada de turnos, uma vez que refletem a influência do gênero dos falantes no gerenciamento da tomada de turnos. Cabe aqui uma ressalva no que se refere ao sistema de tomada de turnos descrito pelos autores que consideram esse sistema como uma forma básica de organização da conversa, invariável, mas não insensível, ao número de participantes, e generalizável para qualquer conversa, uma vez que a fala-em-interação é "passível de acomodar uma imensa gama de FREITAS, Ana Luiza Pires: MACHADO, Zenir Flores Noções fundamentais a organização da tomada de turnos na fala-em interação In LODER, L L: JUNG, N M (Org) Fala-em-interação social introdução à análise da nversa etnometodológica Campinas Mercado de Letras, 2008 p 59-94

2

ALMEIDA. Alexandre Nascimento A Construção de masculinidades na fala-em-interação em cenários escolares 2009 Tese (Doutorado) - Universidade Federal do Rio Grande do Sul, Porto Alegre, 2009 participantes, mostrando-se adaptável a eles" ${ }^{1}$. Desse modo, o sistema de troca de turnos é, ao mesmo tempo, "livre" de contexto e "sensível" ao contexto $^{2}$. Schegloff apresenta, em 2000, quatro instâncias em que a fala em sobreposição é trabalhada pelos participantes de maneira não problemática e descreve algumas práticas empregadas pelos sujeitos ao lidarem com as sobreposições "problemáticas" que podem revelar o investimento de um dos participantes em outras questões, cuja identificação no momento da interação pode ser possível para seu interlocutor. A influência de fatores exógenos mencionados por West e Zimmerman é, portanto, contemplada pelos estudos da Análise da Conversa Etnometodológica.

No quinto capítulo, “Quem está interrompendo? Questões de dominação e controle”, Tannen acrescenta um ângulo diferente à análise para que se perceba que, nem sempre, o fato de alguém sentir-se interrompido 
em uma conversação significa, de fato, que um outro intencionalmente desejou interromper a sua fala ou o seu turno de fala. Torna-se importante analisar a sistêmica das conversações, verificando a dinâmica e contexto em que essas ocorrem, para identificar uma interrupção. Isso implica não apenas anotar, de forma mecanicista o número das pretensas interrupções, mas conhecer os falantes, contexto e conteúdo, além da situação em que estão ocorrendo as conversas. A interrupção é, nesse caso, uma questão de interpretação quanto aos direitos, expectativas e obrigações individuais. Para Tannen, os falantes possuem estilos conversacionais diferentes, o que torna a questão ainda mais complexa. Isso é observado por meio do conceito de falantes de alta consideração e falantes de alto envolvimento, ou seja, falantes de alto envolvimento fazem interrupções cooperativas, pois aparentemente constroem a conversa, contribuindo com o seu conteúdo, sem mudar o tópico, elaborando-a. Em diferentes contextos, entre falantes com diferentes estilos conversacionais, tais sobreposições podem ser malsucedidas, quando o falante de alta consideração se sente metralhado por perguntas, por meio de interrupções, por um falante de alto envolvimento.

De forma conexa e pertinente, o artigo procura articular gênero e cultura como elementos concernentes à forma pela qual se interpretam construções e estilos conversacionais, salientando o fato de pessoas de mesma origem cultural apresentarem similaridade na forma de falar, pontuando, oportunamente, que isso pode representar tanto um benefício quanto um risco. Esse é o caso em que as formas de falar servem como base para estereótipos negativos, como exemplo, o modo pelo qual o antissemitismo geralmente descreve os judeus: escandalosos, agressivos e grosseiros.

A autora conclui trazendo a questão para a discussão de gênero e linguagem, e sugere que diferenças de gênero funcionam na comunicação intercultural como uma forma de traição, uma tentativa de mascarar a dominação real sob o disfarce da diferença cultural. O trabalho de Tannen avança quando propõe articular etnia e gênero, mas esse avanço não é observado na análise de dados: mulheres continuam sendo somente mulheres e homens somente homens.

No sexto capítulo, “Comunidades de práticas: lugar onde coabitam linguagem, gênero e poder”, Penelope Eckert e Sally McConnell-Ginet iniciam com uma contundente afirmação: nos estudos de gênero e linguagem há abstração em demasia. Para elas, os embasamentos teóricos não são capazes de conferir suporte coerente o bastante para fundamentar, de forma integrada às práticas e realidades sociais, os estudos sobre linguagem, gênero e relações de poder. Desse modo, as pesquisadoras propõem conectar cada uma das caracterizações abstratas de identidade às práticas linguísticas, de forma a possibilitar o exame das especificidades de sua realização 
concreta em comunidades reais. Para tanto, apresentam como unidade de análise social o conceito de comunidades de prática, por permitir explicar a construção não só da linguagem como também do gênero. Segundo Eckert e McConnell-Ginet, é o engajamento mútuo dos agentes humanos em ampla gama de atividades que cria, sustenta, desafia e, por vezes, muda a sociedade e suas instituições, incluindo gênero e linguagem. Os locais de tal engajamento mútuo são as comunidades. Nesse caso, as comunidades de prática são definidas pelo engajamento social dos falantes e não simplesmente pela localização desses falantes, e são elas que estruturam socialmente a comunidade.

Esse foco possibilita ver o indivíduo como articulador de uma variedade de formas de participação em múltiplas comunidades de prática, e a identidade individual é baseada na multiplicidade dessa participação. Trata-se de um conceito fértil, conforme evidenciou a análise de dados de um contexto multilíngue (alemão, português, brasileiro), no qual homens e mulheres se orientam de modo diferente em relação à identidade étnica alemã e tudo o que está associado a essa identidade na comunidade ${ }^{3}$.

A seguir, em “'É uma menina!': a volta à performatividade linguística”, uma tradução do capítulo introdutório do livro organizado por Anna Livia e Kira Hall, intitulado Queerly phrased, marco da literatura sob a perspectiva queer, problematiza-se o fato de que a maioria dos estudos sobre gênero pressuponha gênero como categoria não problemática, indicialmente ligada ao sexo do falante. Partindo de uma concepção discursiva pós-moderna de linguagem - o significado das palavras é construído no discurso - e de um retorno à teoria dos atos de fala, principalmente com teóricas da linguística queer, o gênero é apresentado como performativo porque configura a sua existência por meio do próprio pronunciamento. Elocuções de gênero, como o pronunciamento apresentado no título do capítulo "É uma menina”, nunca seriam meramente descritivas, mas prescritivas, exigindo que a endereçada aja de acordo com as normas vinculadas a gênero. Nesse caso, gênero é considerado não simplesmente como algo que se adeque às palavras para o mundo, mas como algo que adeque o mundo às palavras pronunciadas.

E, no último capítulo, "Desempenhando identidade de gênero: conversas entre rapazes e construção de masculinidade heterossexual”, Deborah Cameron analisa uma sequência de conversas informais entre cinco rapazes que, além de assistirem a um jogo de basquete na TV, conversam. A autora também admite uma concepção discursiva de linguagem, considerando o gênero como performativo: um constituinte da identidade que a pessoa pretende ter. Como resultado de sua análise, ela argumenta que é inútil usar modelos generificados que considerem, implicitamente, mas-

culinidade e feminilidade como entidades imutáveis, rígidas e previsíveis, como no estudo feito por seu aluno, um dos participantes da conversa, que relatou que os dados confirmaram o estereótipo das interações exclusiva- 
mente masculinas, ou seja, que eles conversaram sobre "vinho, mulher e esportes". Para ela, os assuntos de que tratam ao longo da conversa demonstram a ansiedade tradicional dos rapazes quanto a serem sempre vistos como homens heterossexuais viris e não como mulheres ou homossexuais.

A apresentação de Linguagem, gênero, sexualidade: clássicos traduzidos, além de constituir um marco nos estudos da temática no Brasil, contribui para fortalecer os grupos de diferentes áreas que trabalham com a questão, uma vez que possibilita a um público mais amplo, especialmente profissionais da área da educação, conhecer o tema e refletir sobre ele.

\section{NEIVA MARIA JUNG}

Docente da Universidade Estadual de Maringá - PR

neivajung@yahoo.com.br

\section{MARIA AMÉLIA LOBO PIRES}

Discente não regular do Programa de Pós-Graduação em

Letras da Universidade Estadual de Maringá - PR

ma_lobopires@yahoo.com.br 